\title{
A description of liver function tests amongst adult patients in the British Columbia Home Parenteral Nutrition (BC HPN) Program who have changed from a soybean oil emulsion to a mixed-lipid emulsion
}

Broening $J^{1}$, Tsai $J^{1}$, Lewis $\mathrm{V}^{2}$, Richardson $\mathrm{A}^{2}$, Koh $\mathrm{JC}^{2}$, Thornhill $\mathrm{J}^{2}$, Kafka $\mathrm{T}^{1}$

${ }^{1}$ UBC Dietetics Program, British Columbia, ${ }^{2}$ Providence Health Care, British Columbia

\section{INTRODUCTION}

Intravenous lipid emulsions (ILEs) refer to the fat component of parenteral nutrition (PN), a form of nutritional therapy for patients who cannot feed entirely via the gastrointestinal tract. However, long-term ILE use may be associated with PN-associated liver disease (PNALD) ${ }^{1}$. Soybean oil (SO)-based ILE, e.g. Intralipid ${ }^{\circledR}$ may contribute to disease development ${ }^{1}$. Consequently, SMOFlipid ${ }^{\circledR}$, a mixed oil-based ILE has been developed ${ }^{1-3}$. Current literature suggests a role for SMOFlipid ${ }^{\circledR}$ in preventing, treating, or managing PNALD in acute-care and surgical settings ${ }^{4-6}$. However, a gap in knowledge still exists regarding its use for adult patients on home PN, where ILEs are used long-term.

Purpose: To describe the liver function tests of adult patients in the BC HPN Program pre- and post-transition to SMOFlipid $^{\circledR}$ from Intralipid ${ }^{\circledR}$ and to use demographic and clinical data to characterize possible patterns of change.

\section{METHODS}

\section{Study population}

- Adult patients who transitioned from Intralipid ${ }^{\circledR}$ to SMOFlipid ${ }^{\circledR} \&$ were active in the BC HPN program between Jan. 1, 2013 to Oct. 31, 2017

- Convenience sampling was used $(n=23)$

Retrospective Chart Review

- Data recorded included:

- Demographic \& clinical characteristics

- Monthly measurements of LFTs (serum alkaline phosphatase [ALP], alanine aminotransferase [ALT], aspartate aminotransferase [AST], Total Bilirubin) for the 6 months before and after transition to SMOFlipid $^{\circledR}$

Data analysis

- Descriptive statistics was used

- Frequency and percentages for categorical variables

- Mean (SD) for numerical variables; if data was largely skewed, median (IQR) used

- Grand means for LFTs pre- \& post-SMOFlipid ${ }^{\circledR}$ transition

- All analysis performed in Excel 2010

:LFT Definitions

- Normal if fell within St. Paul's Hospital reference ranges:

- AP: 30-105 U/L; ALT: $15-55$ U/L; AST: 15-45 U/L; Total Bilirubin: $<20 \mu \mathrm{mol} / \mathrm{L}$

- Abnormal if levels are outside the reference range

- Severity based on degree of elevation ${ }^{7}$ :

- AP/ALT/AST: mild (<2x normal), moderate (2-5x normal), : and severe (>5 times normal)

- Total Bilirubin: mild (25.65-32.49 $\mu \mathrm{mol} / \mathrm{L})$, moderate $(34.2-51.3 \mu \mathrm{mol} / \mathrm{L})$, severe $(>51.3 \mu \mathrm{mol} / \mathrm{L})$

\section{REFERENCES}


Table 1. Patient Characteristics at Date of Assessment

\begin{tabular}{|c|c|}
\hline & $(n=10)$ \\
\hline Age, years, mean \pm SD & $65.3 \pm 8.58$ \\
\hline Male/female, $\mathrm{n}$ & $5 / 5$ \\
\hline Weight, kg, mean \pm SD & $61.3 \pm 12.52$ \\
\hline BMI, $\mathbf{k g} / \mathrm{m}^{2}$, mean $\pm \mathrm{SD}$ & $21.79 \pm 2.61$ \\
\hline $\begin{array}{l}\text { Presence of liver disease } \\
\text { Yes/No, } n\end{array}$ & $1 / 9$ \\
\hline $\begin{array}{l}\text { Presence of inflammatory bowel } \\
\text { disease } \\
\text { Yes/No, } n\end{array}$ & $4 / 6$ \\
\hline $\begin{array}{l}\text { Indication for HPN } \\
\text { SBS/Other, } n\end{array}$ & 9/1 \\
\hline NPO/PO, n & $1 / 9$ \\
\hline Duration of parenteral nutrition & $1512(652.8-3858)$ \\
\hline
\end{tabular}

Table 2. HPN intake

\begin{tabular}{r|ll} 
& \multicolumn{1}{l}{$\begin{array}{l}\text { Intralipid® 20\%, } \\
\text { Mean } \pm \text { SD }\end{array}$} & $\begin{array}{l}\text { SMOFlipid® 20\%, } \\
\text { Mean } \pm \text { SD }\end{array}$ \\
\hline $\begin{array}{r}\text { HPN calories (daily } \\
\text { average), kcal, }\end{array}$ & $1435.42 \pm 391.62$ & $1338.76 \pm 458.85$ \\
Avg Lipid intake g/kg/d & $0.59 \pm 0.17$ & $0.57 \pm 0.17$
\end{tabular}

Table 3. Grand mean of LFTs pre- and post-transition to SMOFlipid $\AA$

\begin{tabular}{r|ll} 
& $\begin{array}{l}\text { Intralipid } ₫ 20 \%, \\
\text { Grand mean } \pm \text { SD }\end{array}$ & $\begin{array}{l}\text { SMOFlipid } \Theta 20 \%, \text { Grand } \\
\text { mean } \pm \text { SD }\end{array}$ \\
\hline$A L P, U / L$ & $341.44 \pm 107.99$ & $335.32 \pm 119.04$ \\
$A L T, U / L$ & $60.1 \pm 30.62$ & $44.80 \pm 16.24$ \\
$A S T, U / L$ & $50.58 \pm 14.96$ & $38.07 \pm 11.97$ \\
$\begin{array}{r}\text { Total Bilirubin } \\
\mu \text { mol/L }\end{array}$ & $15.84 \pm 4.42$ & $14.65 \pm 6.38$
\end{tabular}

Overall patterns of change pre- and post transition Pre-post ALP pattern

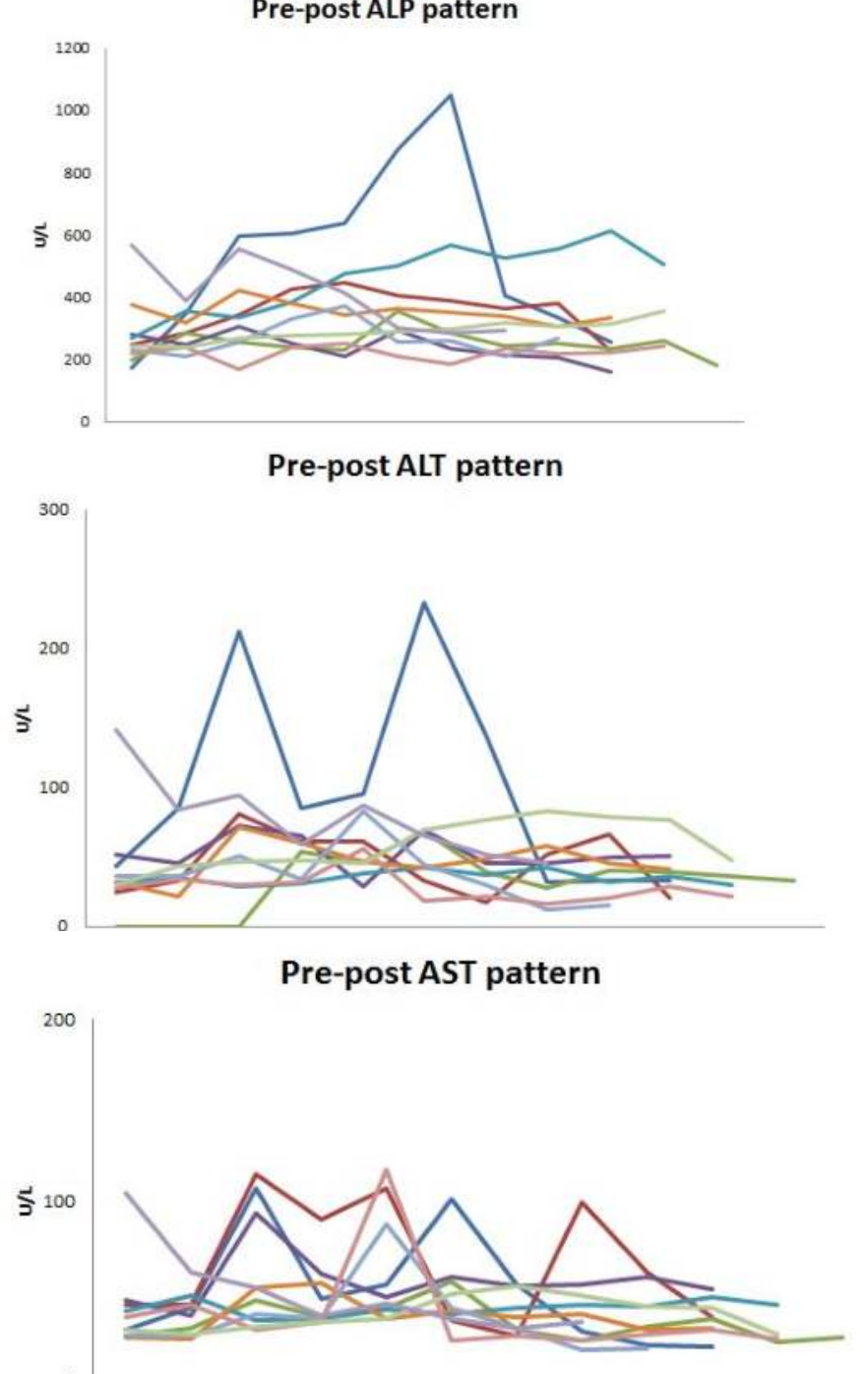

Pre-post Total Bilirubin pattern

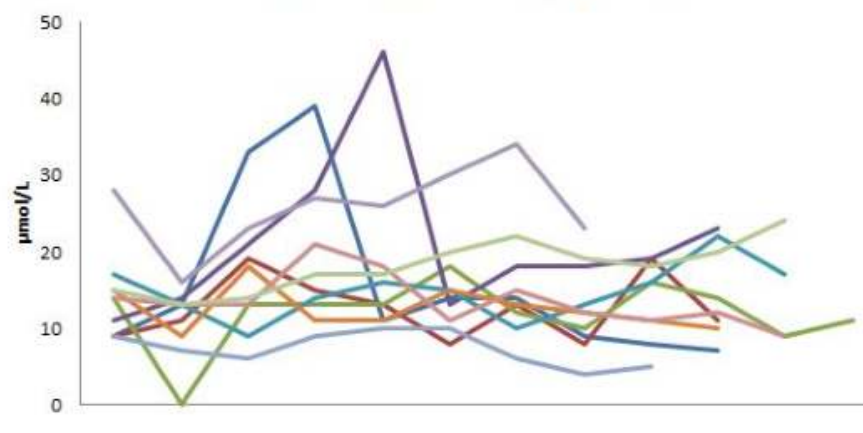

\section{KEY FINDINGS}

- 19 patients constituted the study group

- 6 patients did not have enough LFT measurements for meaningful analysis, 3 had outlier values

- Therefore, analyzed sample $=10$ patients

- Most demonstrated increases in all four LFTs in the 6 month period leading up to transition to SMOFlipid $^{\circledR}$

- After transition to SMOFlipid ${ }^{\circledR}, 70-80 \%$ of participants' LFTs showed a decrease in mean concentration

- Characteristics for a given pattern of change:

- Decrease: more patients were women, had SBS, received HPN for $5+$ years, and received $\geq 0.5 \mathrm{~g} / \mathrm{kg} / \mathrm{d}$ lipid from PN

- Increase: patients $(n=2)$ were over 70 years, had SBS, received HPN for $<5$ years, and received $<0.5$ $\mathrm{g} / \mathrm{kg} / \mathrm{d}$ li[pid from $\mathrm{PN}$

\section{DISCUSSION AND CONCLUSION}

- $50 \%$ of patients demonstrated liver injury while on Intralipid ${ }^{\circledR}$, although none had a cholestatic pattern of injury $^{7}$

- In general, LFTs declined after transition to SMOFlipid ${ }^{\circledR}$, however the level of change and corresponding change in severity is variable

- Findings correspond with literature $\mathrm{e}^{4-6,8-10}$ regarding risk factors for hepatic dysfunction and effects of SMOFlipid ${ }^{\circledR}$ on LFTs

- The majority of studies comparing SO-based ILEs and mixed-lipid ILEs are done in acute and surgical settings ${ }^{4-6}$; our study is to our knowledge the first of its kind in the HPN population and looks at a transition between the two ILEs

- Our study did not correlate LFT improvement to SMOFlipid ${ }^{\circledR}$

\section{Study Limitations}

- Small sample size

- Non-probability sampling

- Determining observed patterns of change subjective

\section{Future Directions}

- Larger sample size

- Longer term observation for more meaningful data

- Consider SMOFlipid ${ }^{\circledR}$ at baseline for HPN patients in order to reduce the risk of liver irritation or injury that may or may not be reversible

\section{ACKNOWLEDGEMENT}

Thank you Andree Richardson, Vanessa Lewis, Jiak Chin Koh, Jaki Thornhill for your guidance and support throughout this project. As well as Annalijn Conklin, for whom we could not do data analysis without. 